\title{
Optical Resolution with Immobilized Enzymes on Nanoparticles
}
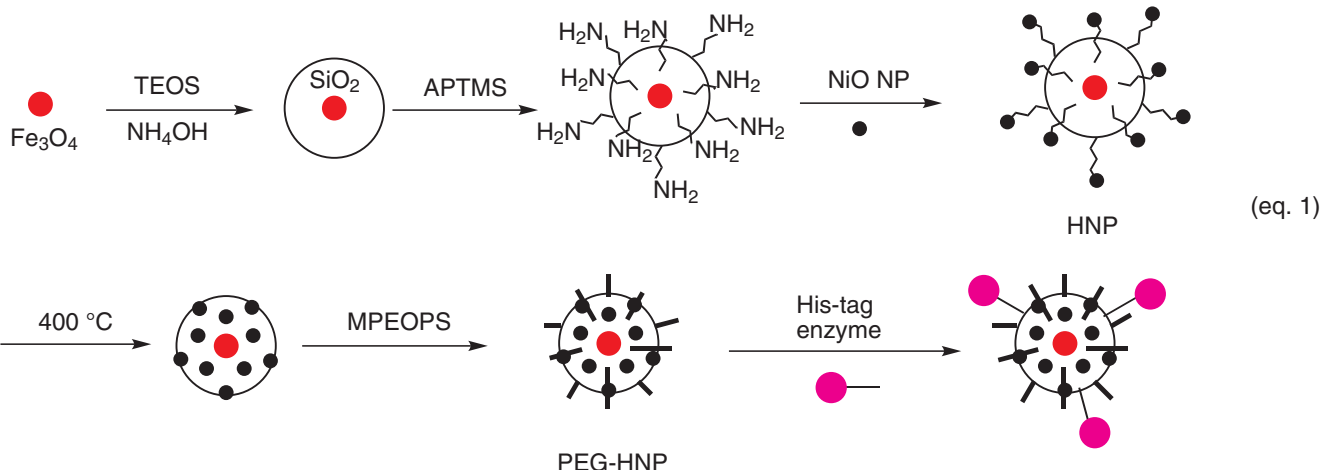

HIS-HNP

TEOS: tetraethylorthosilicate

APTMS: (3-aminopropyl)trimethoxysilane

MPEOPS: 2-(methoxy[polyethyleneoxy]propyl)trimethoxysilane<smiles>c1ccc(C2CO2)cc1</smiles>

racemic styrene oxide

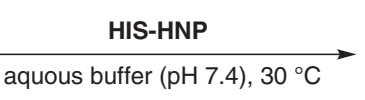

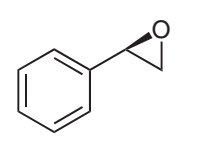

(S)-styrene oxide

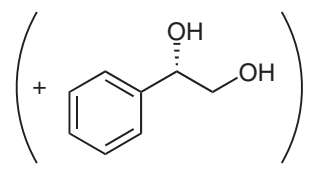

(eq. 2)

\footnotetext{
$1^{\text {st }}$ run: $40.2 \%,>98 \%$ ee (reaction time $25 \mathrm{~min}$ ) $2^{\text {nd }}$ run: $37.5 \%,>98 \%$ ee (reaction time $35 \mathrm{~min}$ ) $3^{\text {rd }}$ run: $35.3 \%,>98 \%$ ee (reaction time $50 \mathrm{~min}$ ) $4^{\text {th }}$ run: $39.5 \%,>98 \%$ ee (reaction time $60 \mathrm{~min}$ ) $5^{\text {th }}$ run: $40.0 \%,>98 \%$ ee (reaction time $90 \mathrm{~min}$ ) $6^{\text {th }}$ run: $40.7 \%$, >98\% ee (reaction time $105 \mathrm{~min}$ )
}

Significance: Enzyme-anchored hybrid nanoparticles (HIS-HNP) were prepared by reaction of Histagged enzymes (epoxide hydrases) with the PEG-HNP-bearing NiO particles (eq. 1). The kinetic resolution of racemic styrene oxide was performed with HIS-HNP to give enantioenriched $(S)$ styrene oxide (>98\% ee). The catalyst was magnetically separated from the reaction mixture and reused five times (eq. 2).
Comment: HNP and PEG-HNP were characterized by ICP-AES, TEM, and SEM analyses. Though the amount of detached enzyme from HIS-HNP was less than $5 \%$ during the reaction, the enzymatic activity decreased as the recycling process was repeated. 